\title{
Research on the Linkage Development and Countermeasures of Manufacturing Industry and Logistics Industry
}

\author{
Qingmin Yuan ${ }^{a}$, Jianan Lei ${ }^{b}$ \\ School of Management of Tianjin Technology University, Tianjin 300384, China \\ a980798984@qq.com, b853570332@qq.com
}

\begin{abstract}
The linkage development of manufacturing industry and logistics industry is an important project in the plan of our country's logistics industry adjustment and revitalization, also its influence has been continued until now. At present, the integration of the manufacturing industry and the logistics industry has become the industry consensus, but there are still some problems need to be concerned. This paper takes the development of manufacturing industry and logistics industry as the main line. According to the present situation of manufacturing industry and logistics industry in China, this paper put forward the necessity of linkage between "two industries" and 4 main problems and suggestions, which provide the basis for the formulation of linkage between logistics industry and manufacturing industry.
\end{abstract}

Keywords: Logistics industry; Manufacturing; Linkage development; Suggestions.

\section{Introduction}

Manufacturing industry is the main industry of national economic activity in China, which is also an important source to logistics demand. The State Council promulgated the 《logistics industry restructuring and revitalization plan (2009-2011)》 in March 2009, then the logistics industry has become the sole producer services among the ten largest industry in the adjustment and revitalization plan. Modern logistics is an accelerator of economic development, which has been a revolutionary impact to manufacturing industry. Logistics has become an important part of the operation and development of manufacturing industry, and manufacturing industry does not work if it has not the blood of modern logistics. Therefore. The manufacturing and logistics industry has the mutual promotion and mutual restriction of interactive relationship.

Practice has proved that the manufacturing industry and logistics industry is highly related and the space of development is large. Comparing to developed countries, China's manufacturing industry is still in the low-end of the industry value chain, the product added-value and technology content is relatively low, and the industry's sustainable development ability is not strong. Promoting the development of manufacturing industry and logistics industry, promoting manufacturing enterprises to implement process re-engineering, implementing specialized operations and optimizing the allocation of resources, will be advantage to reduce logistics costs, improve operational efficiency and enhance core competitiveness. It is also a way to enhance the logistics service capabilities and promote the development of the logistics industry and finally realize the upgrading of the manufacturing industry and the overall improvement of the international competitiveness.

\section{Necessity of linkage development of manufacturing industry and logistics industry}

Manufacturing industry and modern logistics industry mutual support each other. The two industry linkage development and integration provide a good opportunity for development of the two industry during the "Twelfth Five Year", but also provides an important way for China's industrial structure adjustment and changes of economic growth mode. As is known to all, China has developed into a big manufacturing country, but there is a certain gap if comparing with the manufacturing power. China's manufacturing industry is still in the lower level of the world division of labor system. The profit level of labor intensive and low-end manufacturing industry is low, and consumption is large. So sustainable development is difficult to maintain. At the same time, international competition in the manufacturing industry has increased from the cost, resources and technology to the level of 
industrial integration development. China's manufacturing industry to achieve the transition from a superpower to a super power, must shift to the low consumption, high output direction, and must be integrated management. The linkage development of manufacturing and logistics industry provides an effective way for manufacturing industry transformation. The logistics industry is a production type service industry which is separated from the circulation, and has the nature of connection with supply chain and the ability of mining enterprise third profit source. Logistics industry should be embedded in the manufacturing industry with a professional team to undertake the logistics business of manufacturing enterprise.

The two industry linkage is the inevitable way to realize social and professional development of logistics industry. From the view of the development of logistics industry, the development of manufacturing industry is an important prerequisite and inevitable process of logistics socialization development. For example, Haier logistics development is closely linked with the production of Haier group, the first is to meet the needs of the production of the Haier group, and then gradually expanded to meet the needs of the global home appliance manufacturing customers. Manufacturing and logistics industry is a symbiotic relationship. To improve the logistics of the manufacturing industry and promote the adjustment of industrial structure, not only is conducive to the development of the logistics industry, manufacturing industry will also get the opportunity to develop rapidly, which will be the inevitable trend of the future development of the two industry linkage. From the perspective of rational economic man, the cost benefit of the two industry linkage is analyzed through the game model. Neither cooperation nor outsourcing, the two sides have $2 \mathrm{~m}$. If the two industry only choose a kind of cooperation, the resulting loss of assets is b-a. In both case of cooperation and outsourcing, the two sides obtain the maximum benefits $2 \mathrm{p} .(2 \mathrm{p}>\mathrm{b}-\mathrm{a}>2 \mathrm{~m})$

\begin{tabular}{|c|c|c|}
\hline $\begin{array}{c}\text { Manufacturing industry } \\
\text { Logistics industry }\end{array}$ & Non cooperation & Cooperation \\
\hline Non outsourcing & $\mathrm{m}, \mathrm{m}$ & $\mathrm{b},-\mathrm{a}$ \\
\hline Outsourcing & $-\mathrm{a}, \mathrm{b}$ & $\mathrm{p}, \mathrm{p}$ \\
\hline
\end{tabular}

Fig. 1 Analysis on the game between manufacturing and logistics in logistics outsourcing

\section{Present situation of manufacturing industry and logistics industry}

\subsection{Present situation of manufacturing industry.}

Manufacturing industry is the main economic growth of our country, the basis of economic transformation and the embodiment of international competition. Its development and upgrading established the initial status of "manufacturing power" of China. According to statistics, China's industrial added value was 21068940000000 yuan in 2013, an increase of $162 \%$ over 2008. However, there still exists some problems, such as low labor productivity low core technology and poor innovation capability which cause low a considerable gap from the "manufacturing power" position.

\subsection{Present situation of logistics industry.}

Compared with the manufacturing industry, although China's logistics industry started late, but the development momentum is good, logistics infrastructure, technology and equipment level continues to improve, which lay a solid foundation to achieve the integration of supply chain. According to statistics, China's total social logistics production value in 2013 was nearly 2728200000000 yuan, accounting for $4.8 \%$ of GDP and $10.4 \%$ of service industry added value. The national operating railway mileage has been up to 66585 kilometers. But at present, China's logistics industry is still in a low level. Such as the market system and management system is not perfect, basic facilities and technical equipment is relatively backward, regional differences in logistics development, the lack of high-end talent and green logistics lags behind other issues. 


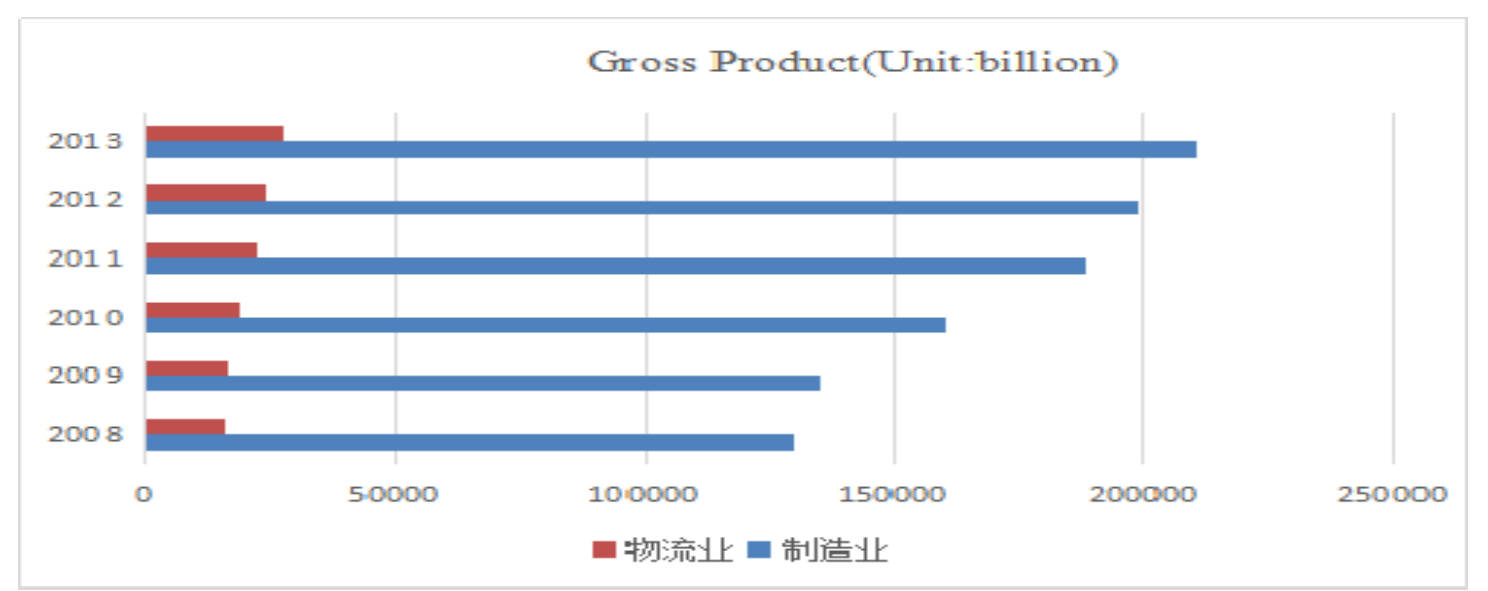

Fig. 2 China's manufacturing industry and logistics industry (2008-2013)

\subsection{Present situation of linkage between manufacturing industry and logistics industry.}

With the development of information and communication technology and the extensive application, the boundary between the service industry and manufacturing industry is becoming increasingly blurred. Logistics industry as one of the important producer services, improve the level of production and production efficiency, through the complementary and integration of the industry chain which is the inevitable choice to promote the industrial structure upgrade and promote the development of the logistics industry. First of all, China has a great advantage in the manufacturing industry from the overall development of the speed and scale of view. The development speed and scale of manufacturing industry is far better than the logistics industry. Secondly, from the perspective of the enterprise, the national manufacturing enterprises accounted for more than logistics enterprises. Finally, from the development of the situation, the linkage development of logistics industry and manufacturing industry is mainly concentrated on automobile, electronics, home appliances, medicine, equipment manufacturing in the Pearl River Delta region. The linkage degree of those industry is higher.

\section{Analysis on the existing problems}

(1)Lack of mutual trust mechanism. In order to realize the linkage between manufacturing enterprises and logistics enterprises, some commercial information of manufacturing enterprises must be fully disclosed to the third party logistics enterprises, which makes the supply chain information more transparent. At present, many manufacturing enterprises are not willing to fully open their own procurement channels, process and other business secrets. These results cause some questions, such as the linkage development of the two industry is not deep, the level is not high.

(2)Limited cooperation. Manufacturing enterprises scattered in various departments of the logistics demand, which have not completely transformed into social needs, are subject to effective communication. At the same time, due to the lack of social logistics demand, logistics enterprises do not understand the real needs of manufacturing enterprises, which restricts the development of professional logistics. Leading to contradiction of insufficient effective demand and supply capacity is not enough to coexist, and the manufacturing enterprises and logistics enterprises is difficult to leveraging each other.

(3)The structural contradiction between supply and demand is in the different level of manufacturing industry and logistics industry. China's manufacturing industry and logistics industry is relatively fast, but the manufacturing industry and the logistics industry linkage is lagging behind.

(4)The export - oriented manufacturing industry causes unbalanced development of the industry between the east regions and rest regions. Logistics investment is not enough and the logistics costs are relatively high in the central-western regions, which cause that the development level of logistics industry is low and the development is difficult in the region's. 
In addition, there still exist some objective factors that also restrict the linkage development of the two industry. Such as, the market order is not standardized, information technology is backward, logistics service system is lack of standardization.

\section{Suggestions on the linkage development of manufacturing industry and logistics industry}

In view of the above problems, the following suggestions are put forward for the development of manufacturing industry and logistics industry in China.

For manufacturing enterprises, changing the concept of enterprises should change the concept of "big and complete, small and complete" development model. Logistics enterprises should be encouraged to outsource the logistics business and strip some non-core logistics demand. To recognize the consistency of interests between logistics service and the manufacturing enterprises, they should focus on the innovation of logistics cooperation mode and make the logistics management of the manufacturing enterprises.

Sound credit mechanism of the linkage of the two industry. Honesty is the basis for the linkage development of the two industry. Both sides need to increase business transparency and establish mutual trust and win-win development of the faith. Logistics enterprises should improve the integrity of the enterprise system, achieve national or industry related credit certificate and should improve the credit guarantee mechanism, to meet customer needs in good faith service. Manufacturing enterprises should also build the appropriate credit evaluation mechanism to ensure the linkage development of business smoothly.

To encourage the separation of logistics business in China,such as logistics operation discrete or logistics outsourcing. The logistics industry should be encouraged to actively intervene in the manufacturing industry and provide integrated supply chain services, and then take effective measures to gradually resolve the structural contradictions of logistics business supply and demand at different levels, finally promote the linkage development of manufacturing and logistics industry.

Establish and organize the implementation of linkage development demonstration projects and key projects further. Promoting the linkage between manufacturing and logistics industry actively, strive for taking the two industry linkage development as an important starting point to promote the optimization and upgrading of industrial economy, promote the two industry linkage as an important part of promoting new industrialization, improve the phenomenon of logistics investment in the central and western regions and the higher logistics costs by carrying out demonstration projects and key projects.

\section{Summary}

With the expansion of logistics demand and the pressure of rising costs, more and more manufacturing enterprises begin to pay more attention to the integration of logistics function, the implementation of process re-engineering and the separation of outsourcing logistics business in order to focus more on the core competitiveness of the building. Therefore, the linkage development is the inevitable trend of the future development of the manufacturing industry and service industry. The trend of the future development of the manufacturing industry and service industry also makes the research on the linkage development mode and path of manufacturing industry and logistics industry. It is a strategic topic that the theory circle and the practice circle are concerned.

\section{Reference}

[1]WANG Xiao-yan. Mechanism \& Mode on Joint Development of Manufacturing and Logistics Industries [J].Logistics Technology, 2009, 28(7).

[2]HUANG Youfang,YAN Wei.Trends and recommendations on intergrated development between manufacturing and logistics industries in China[N].Journal of Shanghai Maritime Univeristy, 2010,3. 
[3]LIU Wen. Concise Remarks on the Interactive Development of Manufacturing Industry and Logistics Industry [J].China's Circulation Economy, 2011, 10.

[4]SU Qin, ZHANG Yan. International Comparison and Research on the Interactive Development of Manufacturing and Logistics Industries [J].Soft Science in China, 2011(5).

[5]BENNETT M J,NOCE T E,er al.Cone penetration test and soil boring at the Bayside groundwater project in San Lorenzo[R]. Alameda County, 2009.

[6]Institute for Supply Management(ISM).Manufacturing ISM report on business[R].Tempe: ROB Media Relations, 2008. 